\title{
The importance of preventive dental visits from a young age: systematic review and current perspectives
}

This article was published in the following Dove Press journal:

Clinical, Cosmetic and Investigational Dentistry

19 March 2014

Number of times this article has been viewed

\author{
Vaishnavi Bhaskar' \\ Kathleen A McGraw ${ }^{2}$ \\ Kimon Divaris ${ }^{3}$ \\ 'Department of Health Policy \\ and Management, Gillings School \\ of Global Public Health, ${ }^{2}$ Health \\ Sciences Library, ${ }^{3}$ Department of \\ Pediatric Dentistry, School of \\ Dentistry, University of North \\ Carolina at Chapel Hill, Chapel \\ Hill, NC, USA
}

\begin{abstract}
Background: Dental caries, the most common childhood chronic disease, disproportionately affects vulnerable parts of the population and confers substantial impacts to children, families, and health systems. Because efforts directed toward oral health promotion and disease prevention are fundamentally superior to dental rehabilitation secondary to disease development, early preventive dental visits (EPDVs) are widely advocated by professional and academic stakeholders. The aim of this comprehensive review was to critically review and summarize available evidence regarding the effectiveness of EPDVs in improving children's oral health outcomes.
\end{abstract}

Materials and methods: A systematic literature search of the PubMed and Embase electronic databases was undertaken to identify peer-reviewed publications investigating the effectiveness of EPDVs on oral health outcomes, including clinical, behavioral, and cost end points up to October 30, 2013. Outcomes of the identified studies were abstracted and summarized independently by two investigators.

Results: Four manuscripts met the inclusion criteria and were included in the review. All studies were conducted in the US and employed a retrospective cohort study design using public insurance-claims data, whereas one study matched claims files with kindergarten state dental surveillance data. That study found no benefit of EPDVs in future clinically determined dental caries levels in kindergarten. The other three studies found mixed support for an association of EPDVs with subsequent more preventive and fewer nonpreventive visits and lower nonpreventive service-related expenditures. Selection bias and a problem-driven dental care-seeking pattern were frequently articulated themes in the reviewed studies.

Conclusion: The currently available evidence base supporting the effectiveness of EPDVs and the year 1 first dental visit recommendation is weak, and more research is warranted. The benefits of EPDVs before the age of 3 years are evident among children at high risk or with existing dental disease. However, EPDVs may be associated with reduced restorative dental care visits and related expenditures during the first years of life.

Keywords: prevention, children, dental visits, anticipatory guidance, dental home, caries

\section{Introduction}

The importance of oral health in the early years of life is well documented, and advocated by professional and academic stakeholders worldwide. ${ }^{1-3}$ Importantly, early childhood oral health influences and outcomes are considered pivotal in determining oral health trajectories across the life course, and can impact oral health and disease occurrence in adulthood. ${ }^{4,5}$ Specifically, early childhood caries, the most common chronic childhood disease, is known to disproportionately affect vulnerable parts of the population and confer substantial impacts to children, families, and health systems. ${ }^{6}$ The list of possible sequelae of early childhood caries is long, and includes dental and
Correspondence: Kimon Divaris Department of Pediatric Dentistry, School of Dentistry, Brauer Hall 228, CB 7450, University of North Carolina at Chapel Hill, Chapel Hill, NC 27599-7450, USA

Tel + I 9195373556

$\mathrm{Fax}+19195373950$

Email kimon_divaris@unc.edu 
medical consequences, pain, diminished quality of life, lost time (children's from school and caregivers' from work or other activities), increased expenditures, and others. ${ }^{7}$

Despite significant strides in foundational sciences and the practice of clinical dentistry during the last few decades, the burden of childhood caries has persisted in most populations. In fact, evidence indicates that oral health disparities may actually be on the increase. ${ }^{8,9}$ Population-based strategies focused on prevention of oral disease are warranted to reduce these disparities. Moreover, efforts directed toward disease prevention are fundamentally superior to dental rehabilitation secondary to disease development when viewed from social justice, human rights, and health-promotion perspectives. ${ }^{10}$ Nevertheless, common preventive protocols, such as the schedule and periodicity of routine dental visits, are not supported by a solid evidence base. ${ }^{11,12}$ Similarly, uniform recommendations for early preventive dental visits (EPDVs) for infants and children have been challenged with regard to the evidence base supporting their timing and benefit to different population groups. ${ }^{13-15}$

Various recommendations regarding the timing of children's first dental visit are available in the public domain, emanating predominantly from nonauthoritative sources. ${ }^{16,17}$ Currently, major professional associations' (American Academy of Pediatric Dentistry, European Academy of Pediatric Dentistry, American Dental Association, Canadian Dental Association, Australian Dental Association, and American Academy of Pediatrics) recommendations converge to the first dental visit taking place early, at the time of the first tooth eruption (around age 6 months) or by age 1 year. ${ }^{18-21}$ Despite these recommendations, the presence of visible caries lesions or dental trauma appear to impel most children's first dental visit. ${ }^{22,23}$ Compounding this frequently problem-initiated pattern of care seeking, caregivers' ability to recognize early signs of dental caries in very young children is limited. ${ }^{24}$

The current rationale for EPDVs, above and beyond the delivery of such preventive services as fluoride treatment, includes the concepts of establishment of a dental home, anticipatory guidance, and risk assessment. ${ }^{15,18,25,26}$ Because caregivers' role is a major influence on their children's oral health behaviors and outcomes, ${ }^{5,27,28}$ EPDVs offer an opportunity to educate caregivers of young children regarding optimal oral hygiene, feeding practices, and dental attendance, and prevention of early childhood caries and dental trauma. ${ }^{29-34}$ Nevertheless, evidence on the effectiveness of preventive dental visits from a young age in improving children's oral health outcomes is scarce. To add to the knowl- edge base of EPDVs, we carried out a comprehensive review of recommendations and published evidence regarding the benefits of EPDVs. Accordingly, our aim was to systematically review and summarize current evidence regarding the effectiveness of EPDVs in improving children's oral health outcomes.

\section{Materials and methods}

We conducted a comprehensive literature search of PubMed and Embase via Elsevier electronic databases to identify relevant published studies. The search strategy combined sets of terms covering three concepts: early preventive dental visits, outcomes, and infants or preschool children. The following search was used in PubMed and modified for the Embase via Elsevier platform: (dental[tw] OR dentist*[tw]) AND (visit*[tw] OR appointment*[tw]) AND (prevent*[tw] OR early[tw]) AND (quality of life[tw] OR absenteeism*[tw] OR outcome*[tw] OR utilization[tw] OR economics[subheading] OR cost[tw] OR costs[tw] OR expenditure*[tw] OR nonpreventive [tw] OR restorative[tw] OR emergenc* $[\mathrm{tw}] \mathrm{OR}$ health behavior[mesh] OR oral hygiene[tw] OR decay[tw] OR caries[tw] OR dmft[tw]) AND (infant [mesh] OR infant* [tw] OR baby [tw] OR babies [tw] OR newborn [tw] OR neonate* [tw] OR child, preschool [mesh] OR preschool child* [tw] OR young child* [tw]). No limits based on language, country or publication year were used. Gray literature, such as reports and conference proceedings, were excluded from Embase search results. The search was initially conducted in August 2013, and was last updated on October 30, 2013. During the last update, our knowledge of the newly released study online by Beil et $\mathrm{al}^{35}$ made us aware that the complexity of language used to describe young children might exclude retrieval of articles not yet indexed in PubMed. As a result, we also searched using only the EPDV part of the search and examined all the nonindexed articles for relevance.

To aid in study identification, we developed inclusion and exclusion criteria (Table 1) based on the objective of this review, in the following categories: study population (children age 0-6 years), type of dental services (dental office-based oral evaluation and prevention services), and study outcomes (oral health-related clinical, behavioral, or expenditure outcomes). For this review, we excluded studies involving children with special health care needs and those published in languages other than English. First, the title and abstract were reviewed to determine potential relevance. Second, full texts of all potentially relevant articles were evaluated by two investigators (VB and KD), and the articles meeting the inclusion and exclusion criteria were 
Table I Selection criteria for the inclusion of studies in the systematic review

\begin{tabular}{|c|c|c|c|c|}
\hline \multicolumn{3}{|c|}{ Inclusion criteria } & \multicolumn{2}{|l|}{ Exclusion criteria } \\
\hline $\begin{array}{l}\text { Study } \\
\text { population }\end{array}$ & Type of dental services & Study outcomes & Health needs & Language \\
\hline $\begin{array}{l}\text { Children } \\
\text { aged } 0-6 \text { years }\end{array}$ & $\begin{array}{l}\text { Dental services including oral } \\
\text { examinations and preventive } \\
\text { measures such as fluoride } \\
\text { application and dental prophylaxis, } \\
\text { as well as anticipatory guidance for } \\
\text { the primary caregiver }\end{array}$ & $\begin{array}{l}\text { Studies examining children's } \\
\text { dental clinical (ie, caries), } \\
\text { behavioral (ie, subsequent } \\
\text { dental visits), or cost } \\
\text { (ie, dental-related expenditures) } \\
\text { outcomes }\end{array}$ & $\begin{array}{l}\text { Studies focusing on } \\
\text { children with special } \\
\text { health care needs }\end{array}$ & $\begin{array}{l}\text { Studies published } \\
\text { in languages other } \\
\text { than English }\end{array}$ \\
\hline
\end{tabular}

selected for this review. Finally, the following data from included studies were abstracted in a summary table: location, title, first author's name, type of study, study population, and outcomes, and overall findings independently by two investigators (VB and KD). Although we did not intend a formal quality assessment of the included studies, we did critique their methodology and major findings, and where applicable, this is reported in the "remarks" column of the data-abstraction table.

\section{Results}

Our initial literature search identified 484 manuscripts in PubMed and 90 additional ones in Embase, 45 of which were duplicates, creating a total database of 529. One additional potentially relevant nonindexed article was identified in PubMed during the search update, for a total of 530. After initial screening of titles and abstracts, as described in the Materials and methods section, 24 manuscripts were selected for full-text evaluation. Based on our inclusion and exclusion criteria, four manuscripts were selected for inclusion in this review. ${ }^{35-38}$

All four studies used a retrospective cohort study design and were carried out in the US (Table 2). With the exception of the Savage et $\mathrm{al}^{36}$ report, which was published in 2004, the studies were published recently, in 2012-2013. All studies utilized public insurance (Medicaid, a US social health care program for families and individuals with low income and resources) claims and had large sample sizes, ranging between 9,204 and 36,805 (Table 3). EPDVs were defined using dental claims for preventive care (comprehensive or recall examination, and preventive services including fluoride varnish and dental prophylaxis) with few between-study variations. Three of the studies examined future preventive and nonpreventive dental visits and related expenditures as the primary outcomes. ${ }^{36-38}$ Importantly, in the most recent study, Beil et al ${ }^{35}$ merged public insurance claim files with state kindergarten dental surveillance data, and thus this was the only study using a clinical end point (dental caries, as measured by the decayed, missing, and filled teeth index) as the study outcome. All investigations employed multivariate modeling methods to control for established sociodemographic confounding factors and study-design characteristics. Notably, Sen et al ${ }^{38}$ implemented an additional econometric multivariate modeling strategy based on "individual fixed effects", which according to the authors proved superior and more robust against the effects of selection bias compared to previously used "naïve" modeling approaches.

The Beil et $\mathrm{al}^{35}$ study, among other comparisons, contrasted children who had their first preventive dental visit before versus after age 18 months and found no benefit of EPDV in future clinically determined dental caries levels when children were examined in kindergarten. Savage et $\mathrm{al}^{36}$ found that children who had an EPDV by age 1 year $(n=23$, or $0.24 \%$ of the study sample) were more likely to have future

Table 2 List of studies included in the review of the effectiveness of early preventive dental visits in improving children's oral health outcomes

\begin{tabular}{|c|c|c|c|c|}
\hline Study & PMID & Country (state) & Title & Study type \\
\hline Savage et $\mathrm{al}^{36}$ & 15466066 & USA (NC) & $\begin{array}{l}\text { Early preventive dental visits: effects on } \\
\text { subsequent utilization and costs. }\end{array}$ & $\begin{array}{l}\text { Retrospective } \\
\text { cohort study }\end{array}$ \\
\hline Beil et $\mathrm{al}^{37}$ & 22525611 & USA (NC) & $\begin{array}{l}\text { Effect of early preventive dental visits on } \\
\text { subsequent dental treatment and expenditures. }\end{array}$ & $\begin{array}{l}\text { Retrospective } \\
\text { cohort study }\end{array}$ \\
\hline Sen et $\mathrm{al}^{38}$ & 23713098 & USA (AL) & $\begin{array}{l}\text { Effectiveness of preventive dental visits in reducing } \\
\text { nonpreventive dental visits and expenditures. }\end{array}$ & $\begin{array}{l}\text { Retrospective } \\
\text { cohort study }\end{array}$ \\
\hline Beil et $\mathrm{al}^{35}$ & 24134364 & USA (NC) & $\begin{array}{l}\text { Effects of early dental office visits on dental caries } \\
\text { experience. }\end{array}$ & $\begin{array}{l}\text { Retrospective } \\
\text { cohort study }\end{array}$ \\
\hline
\end{tabular}

Abbreviation: PMID, PubMed ID. 


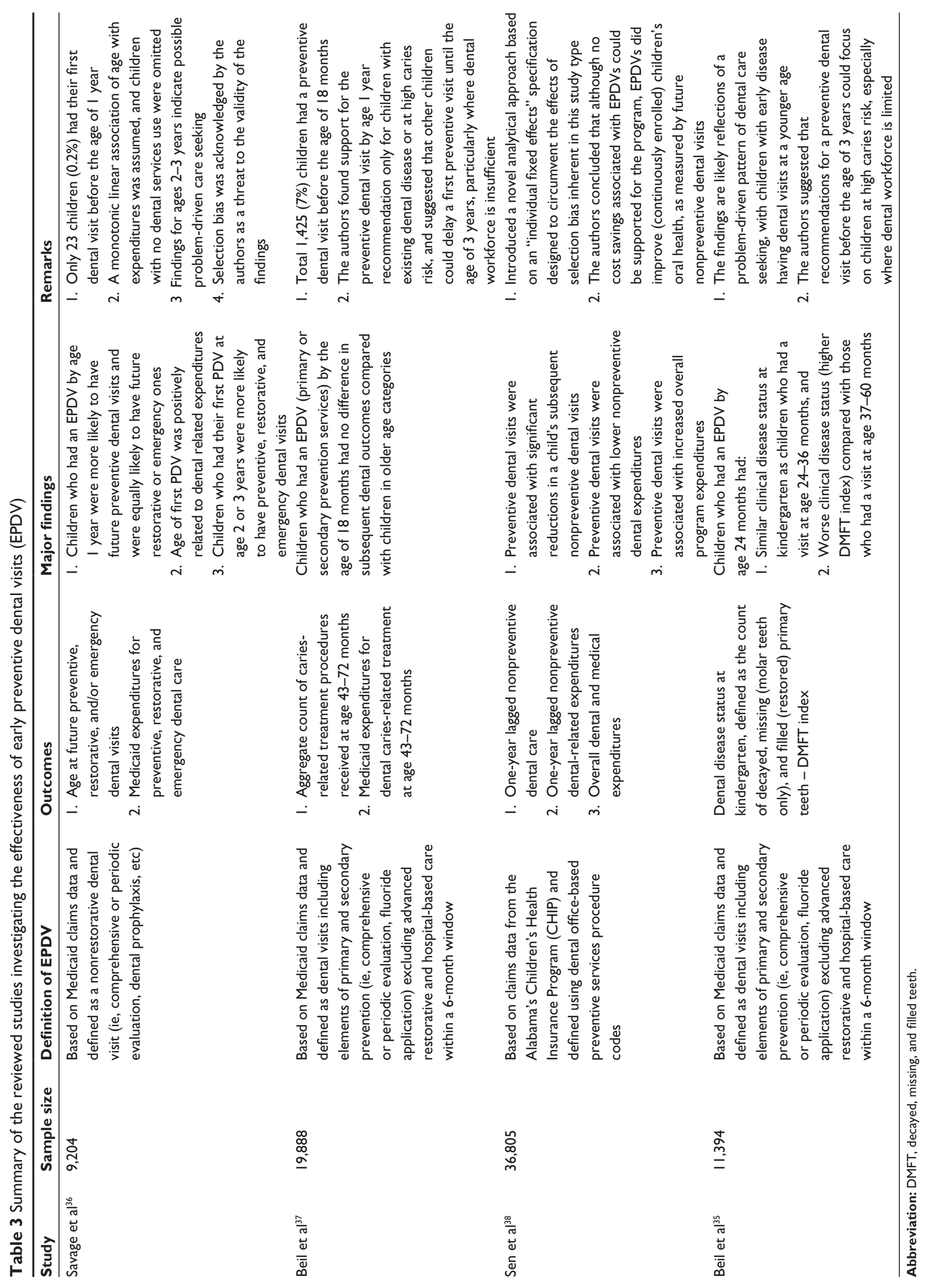


preventive dental visits and were equally likely to have future restorative or emergency ones versus children who had a preventive visit at a later age. These authors also reported a positive association between the age of the first dental visit and future dental-related Medicaid expenditures. In contrast, Beil et $\mathrm{al}^{37}$ did not find any difference in subsequent dental outcomes between children who had primary or secondary prevention services by the age of 18 months and those that received services at an older age. These authors highlighted the possible issues of selection bias and problem-driven dental care-seeking patterns in this type of dental care-service research study. Finally, in the Beil et $\mathrm{al}^{35}$ report, the authors found that preventive dental visits were associated with significant reductions in children's subsequent nonpreventive dental visits and related expenditures, appearing to benefit their oral health. However, they reported that preventive visits were associated with an overall increase in the program's expenditures during the study period.

\section{Discussion}

In this paper, we sought to critically and comprehensively evaluate the evidence base of the effectiveness of EPDVs in improving children's oral health, and found limited evidence in that direction. The only study that considered a clinical end point by investigating dental caries levels at kindergarten did not find any effect of EPDVs. Nevertheless, earlier preventive dental visits appear to be associated with more future preventive visits. Data on EPDVs' effects on subsequent dental treatment (nonpreventive) visits and related costs from three studies are mixed; however, the largest study to date reported an association of EPDVs with fewer future nonpreventive dental visits and lower nonpreventive dental expenditures. While these data provide partial support for EPDVs and the year 1 dental visit, particularly for children at high risk or with existing dental disease, more studies among diverse populations are warranted to add to the evidence base.

The fact that to date there are insufficient data to conclusively support the human and economic benefits of EPDVs for all children does not imply that these benefits do not exist. There is ample theoretical and philosophical support for the benefits of health promotion and primary prevention over disease management and treatment, ${ }^{39-41}$ while EPDVs are consistent with the establishment of a "dental home". 25,26,29 The latter is philosophically aligned to the American Academy of Pediatrics concept of a medical home, where comprehensive pediatric primary care is provided contiguously, in a setting where provider and families "should be able to develop a relationship of mutual responsibility and trust". ${ }^{42}$ Ideally, the establishment of a dental home should take place at a time when provision of anticipatory guidance to caregivers and application of preventive modalities to children can have a true primary preventive effect, prior to the occurrence of disease or traumatic injury. The establishment of a dental home may be especially important for children of caregivers with low health literacy ${ }^{28}$ or socioeconomic disadvantage, ${ }^{43,44}$ and generally those at high risk for dental disease. ${ }^{45}$

Earlier preventive dental visits were associated with more subsequent preventive visits in both the Savage et $\mathrm{al}^{36}$ and Sen et $\mathrm{al}^{38}$ studies, with the total program oral health-related expenditures being positively associated with EPDVs in the latter. The observation that "prevention costs" may not result in immediate program savings is, to some degree, expected. ${ }^{46}$ First, long-term benefits of EPDVs may not be discernible in the 2- to 5-year observation windows of the reviewed studies. Second, possible positive effects on oral health behaviors, wellness, quality of life, pain, and lost time averted due to restorative treatment needs are not easily quantifiable and cannot be readily juxtaposed to dollar expenditures. However, this also offers an opportunity for the conduct of future studies examining the effects of EPDVs using additional oral health-related outcomes, such as caregivers' oral health knowledge and behaviors, and children's oral health-related quality of life.

Despite current professional recommendations for the year 1 dental visit, very few children actually had such a visit, illustrating a complex problem. First, information available to caregivers (ie, freely available online) regarding their children's first dental visit is not always in agreement with the professional recommendations. ${ }^{16,17}$ As most authors noted, patterns of dental care seeking for very young children appear to be problem-initiated rather than driven by primary prevention. Moreover, it is well documented that shortages in the dental workforce (general and pediatric dentists) pose a barrier to access to care for large portions of the population, particularly those enrolled in public insurance and residing in rural areas. ${ }^{47,48}$ In an environment with limited resources, it appears reasonable to support a need- and risk-based prioritization of EPDVs, ${ }^{35,37}$ as low-risk groups may benefit the least from early dental office-based visits. ${ }^{49}$ On the other hand, the task of determining clinical treatment needs and caries risk without an EPDV remains a challenge, because the actual oral health trajectory of individual children is otherwise unobservable.

In this regard, the potential role of nondental providers in screening all young children and referring those at high risk and with treatment is crucial. This model has been success- 
fully implemented in North Carolina, as the Into the Mouths of Babes program, ${ }^{50}$ resulting in improvement of oral health care-services utilization ${ }^{51}$ and reductions of dental cariesrelated treatments among preschool children. ${ }^{52}$ Although econometric evaluations of the program did not reveal any cost savings, ${ }^{53,54}$ this model offers an excellent avenue for the delivery of preventive oral health services (ie, fluoride varnish application) and the conduct of oral health screenings and referrals for specialist care. These services are not offered in a dental setting; however, these visits can be considered EPDVs and further research on their effectiveness in improving children's oral health outcomes is warranted.

\section{Conclusion}

The currently available evidence base supporting the effectiveness of EPDVs and the year 1 first dental visit recommendation is weak, and more research among diverse populations is warranted. Despite the strong theoretical and philosophical support for Benjamin Franklin's “an ounce of prevention is better than a pound of cure", evidence to date has shown benefits of preventive dental visits before age 3 years only among children at high risk or with existing dental disease. Nevertheless, EPDVs are associated with more subsequent preventive dental visits, and may be associated with reduced restorative dental care visits and related expenditures during the first years of life.

\section{Disclosure}

The authors report no conflicts of interest in this work.

\section{References}

1. Petersen PE. The World Oral Health Report 2003: continuous improvement of oral health in the 21 st century - the approach of the WHO Global Oral Health Programme. Community Dent Oral Epidemiol. 2003;31 Suppl 1:3-23.

2. National Institute of Dental and Craniofacial Research. Oral Health in America: A Report of the Surgeon General - Executive Summary. Rockville (MD): US Department of Health and Human Services; 2000.

3. Edelstein BL. The dental caries pandemic and disparities problem. BMC Oral Health. 2006;6 Suppl 1:S2.

4. Nicolau B, Thomson WM, Steele JG, Allison PJ. Life-course epidemiology: concepts and theoretical models and its relevance to chronic oral conditions. Community Dent Oral Epidemiol. 2007;35(4): 241-249.

5. Shearer DM, Thomson WM, Broadbent JM, Poulton R. Maternal oral health predicts their children's caries experience in adulthood. $J$ Dent Res. 2011;90(5):672-677.

6. Tinanoff N, Reisine S. Update on early childhood caries since the Surgeon General's Report. Acad Pediatr. 2009;9(6):396-403.

7. Casamassimo PS, Thikkurissy S, Edelstein BL, Maiorini E. Beyond the DMFT: the human and economic cost of early childhood caries. $J \mathrm{Am}$ Dent Assoc. 2009;140(6):650-657.

8. Dye BA, Tan S, Smith V, et al. Trends in oral health status: United States, 1988-1994 and 1999-2004. Vital Health Stat 11. 2007;(248):1-92.
9. Bagramian RA, Garcia-Godoy F, Volpe AR. The global increase in dental caries. A pending public health crisis. Am J Dent. 2009;22(1):3-8.

10. Lee JY, Divaris K. The ethical imperative of addressing oral health disparities: a unifying framework. J Dent Res. Epub November 4, 2013.

11. Sheiham A. Is there a scientific basis for six-monthly dental examinations? Lancet. 1977;2(8035):442-444.

12. Giannobile WV, Braun TM, Caplis AK, Doucette-Stamm L, Duff GW, Kornman KS. Patient stratification for preventive care in dentistry. J Dent Res. 2013;92(8):694-701.

13. Nainar SM, Straffon LH. Targeting of the year one dental visit for United States children. Int J Paediatr Dent. 2003;13(4):258-263.

14. Rayner JA. The first dental visit: a UK viewpoint. Int J Paediatr Dent. 2003;13(4):269.

15. Poulsen S. The child's first dental visit. Int J Paediatr Dent. 2003; 13(4):264-265.

16. Edelstein BL. The age one dental visit: information on the web. Pediatr Dent. 2000;22(2):163-164.

17. Yeap CK, Slack-Smith LM. Internet information on child oral health and the first dental visit. Aust Dent J. 2013;58(3):278-282.

18. American Academy on Pediatric Dentistry Council on Clinical Affairs. Policy on the dental home. Pediatr Dent. 2008-2009; 30(Suppl 7):22-23.

19. Canadian Dental Association. CDA position on first visit to the dentist. 2005. Available from: http://www.med.uottawa.ca/sim/data/Dental/ CDA\%20Position\%20-\%20First\%20Dental\%20Visit.pdf. Accessed November 28, 2013.

20. Widmer R. The first dental visit: an Australian perspective. Int $J$ Paediatr Dent. 2003;13(4):270.

21. Hale KJ. Oral health risk assessment timing and establishment of the dental home. Pediatrics. 2003;111(5 Pt 1):1113-1116.

22. Camargo MB, Barros AJ, Frazão P, et al. Predictors of dental visits for routine check-ups and for the resolution of problems among preschool children. Rev Saude Publica. 2012;46(1):87-97.

23. Donaldson ME, Fenton SJ. When should children have their first dental visit? J Tenn Dent Assoc. 2006;86(2):32-35.

24. Divaris K, Vann WF Jr, Baker AD, Lee JY. Examining the accuracy of caregivers' assessments of young children's oral health status. J Am Dent Assoc. 2012;143(11):1237-1247.

25. Lee JY, Bouwens TJ, Savage MF, Vann WF Jr. Examining the costeffectiveness of early dental visits. Pediatr Dent. 2006;28(2):102-105.

26. Monroy PG. The age-1 dental visit and the dental home; a model for early childhood caries prevention. J Mich Dent Assoc. 2007;89(1):32, 34-36.

27. Weintraub JA, Prakash P, Shain SG, Laccabue M, Gansky SA. Mothers' caries increases odds of children's caries. J Dent Res. 2010;89(9):954-958.

28. Vann WF Jr, Lee JY, Baker D, Divaris K. Oral health literacy among female caregivers: impact on oral health outcomes in early childhood. $J$ Dent Res. 2010;89(12):1395-1400.

29. Edelstein BL. Evidence-based dental care for children and the age 1 dental visit. Pediatr Ann. 1998;27(9):569-574.

30. Kowash MB, Pinfield A, Smith J, Curzon ME. Effectiveness on oral health of a long-term health education programme for mothers with young children. Br Dent J. 2000;188(4):201-205.

31. Nainar SM, Mohummed S. Diet counseling during the infant oral health visit. Pediatr Dent. 2004;26(5):459-462.

32. Ramos-Gomez FJ, Crall J, Gansky SA, Slayton RL, Featherstone JD. Caries risk assessment appropriate for the age 1 visit (infants and toddlers). J Calif Dent Assoc. 2007;35(10):687-702.

33. Lee JY, Divaris K. Hidden consequences of dental trauma: the social and psychological effects. Pediatr Dent. 2009;31(2):96-101.

34. Regen A. First dental visit: why the change from 3 to 1 ? J Mass Dent Soc. 2012;61(3):21.

35. Beil H, Rozier RG, Preisser JS, Stearns SC, Lee JY. Effects of early dental office visits on dental caries experience. Am J Public Health. Epub October 17, 2013. 
36. Savage MF, Lee JY, Kotch JB, Vann WF Jr. Early preventive dental visits: effects on subsequent utilization and costs. Pediatrics. 2004;114(4):e418-e423.

37. Beil H, Rozier RG, Preisser JS, Stearns SC, Lee JY. Effect of early preventive dental visits on subsequent dental treatment and expenditures. Med Care. 2012;50(9):749-756.

38. Sen B, Blackburn J, Morrisey MA, et al. Effectiveness of preventive dental visits in reducing nonpreventive dental visits and expenditures. Pediatrics. 2013;131(6):1107-1113

39. Nowak AJ. Paradigm shift: infant oral health care - primary prevention. J Dent. 2011;39 Suppl 2:S49-S55.

40. Czeresnia D. The concept of health and the difference between prevention and promotion. Cad Saude Publica. 1999;15(4):701-709.

41. Russell LB. Is Prevention Better Than Cure? Washington: Brookings Institution; 1986.

42. [No authors listed]. American Academy of Pediatrics Ad Hoc Task Force on Definition of the Medical Home: The medical home. Pediatrics. 1992;90(5):774.

43. Sohn W, Ismail A, Amaya A, Lepkowski J. Determinants of dental care visits among low-income African-American children. J Am Dent Assoc. 2007;138(3):309-318.

44. Kim Seow W. Environmental, maternal, and child factors which contribute to early childhood caries: a unifying conceptual model. Int J Paediatr Dent. 2012;22(3):157-168.

45. US Department of Health and Human Services. Guide to Children's Dental Care in Medicaid. Woodlawn (MD): Centers for Medicare and Medicaid Services; 2004. Available from: http:/www.medicaid.gov/ Medicaid-CHIP-Program-Information/By-Topics/Benefits/Downloads/ Child-Dental-Guide.pdf. Accessed November 28, 2013.
46. Russell LB. Preventing chronic disease: an important investment, but don't count on cost savings. Health Aff (Millwood). 2009;28(1): 42-45.

47. Okunseri C, Pajewski NM, Brousseau DC, Tomany-Korman S, Snyder A, Flores G. Racial and ethnic disparities in nontraumatic dentalcondition visits to emergency departments and physician offices: a study of the Wisconsin Medicaid program. J Am Dent Assoc. 2008;139(12): $1657-1666$.

48. Logan HL, Guo Y, Dodd VJ, Seleski CE, Catalanotto F. Demographic and practice characteristics of Medicaid-participating dentists. J Public Health Dent. Epub September 18, 2013.

49. Shenkin JD. Early preventive dental visits for low risk children may have limited benefit. J Evid Based Dent Pract. 2013;13(1):31-32.

50. Rozier RG, Sutton BK, Bawden JW, Haupt K, Slade GD, King RS. Prevention of early childhood caries in North Carolina medical practices: implications for research and practice. $J$ Dent Educ. 2003;67(8):876-885.

51. Rozier RG, Stearns SC, Pahel BT, Quinonez RB, Park J. How a North Carolina program boosted preventive oral health services for low-income children. Health Aff (Millwood). 2010;29(12): 2278-2285.

52. Pahel BT, Rozier RG, Stearns SC, Quiñonez RB. Effectiveness of preventive dental treatments by physicians for young Medicaid enrollees. Pediatrics. 2011;127(3):e682-e689.

53. Stearns SC, Rozier RG, Kranz AM, Pahel BT, Quiñonez RB. Costeffectiveness of preventive oral health care in medical offices for young Medicaid enrollees. Arch Pediatr Adolesc Med. 2012;166(10): 945-951.

54. Casamassimo PS. Nothing is free in life - not even prevention! Arch Pediatr Adolesc Med. 2012;166(10):965-966.
Clinical, Cosmetic and Investigational Dentistry

\section{Publish your work in this journal}

Clinical, Cosmetic and Investigational Dentistry is an international, peer-reviewed, open access, online journal focusing on the latest clinical and experimental research in dentistry with specific emphasis on cosmetic interventions. Innovative developments in dental materials, techniques and devices that improve outcomes and patient satisfaction

\section{Dovepress}

and preference will be highlighted. The manuscript management system is completely online and includes a very quick and fair peerreview system, which is all easy to use. Visit http://www.dovepress. com/testimonials.php to read real quotes from published authors. 